\title{
Hypnosis in the Clutch
}

\author{
John Pates* \\ Department of Sport, England \\ *Corresponding author: John Pates, Department of Sport, Hartpury University, hartpury house, Gloucester, gl193be, England
}

\section{ARTICLE INFO}

Received: 幽 November 14, 2019

Published:

Citation: John Pates. Hypnosis in the Clutch. Biomed J Sci \& Tech Res 23(2)2019. BJSTR. MS.ID.003863.

Keywords: Clutch states, Hypnosis, Triggers, Pres-shot routines

\begin{abstract}
The purpose of this study was to investigate the effects of a hypnosis-based intervention on golf performance and a mental state called the 'Clutch' see Swann et al. [1]. The participants in this study were three elite European Tour golfers. The golf performance data was analyzed using an idiosyncratic $A B$ single-subject, multiple baseline, across individual design. The Clutch state data was analyzed using a procedure that monitored the participants internal experience Wollman et al. [2]. The results of the performance data indicated that all three participants mean stroke average decreased from baseline to intervention. For participant 2 and 3 there was only one overlapping data point between baseline and intervention conditions. For participant 1 there were no overlapping data points between baseline and intervention. Finally, each participant reported they had felt the intervention had increased sensations they associated with Clutch states. These results support the hypothesis that a hypnosis-based intervention can improve golf performance and increase feelings and cognitions that are associated with Clutch states. The positive results suggest the intervention strategy has great potential for training elite golfers. Consultancy guidelines for the use of hypnosis within sport is discussed.
\end{abstract}

\section{Hypnosis in the Clutch}

In sport, episodes of superior human functioning (peak performance) have always aroused widespread interest from the sports psychology community. Researchers capturing a narrative account of these personal events generally agree peak performances are often underpinned by peak experiences (an intense positive feeling) and a mental state called flow (a state of optimal joy) see Privette et al. [3].

In the sport psychology literature flow has emerged as the most dominant theme of study producing a wealth of qualitative and anecdotal evidence that show a strong association between flow and athletic performance see Catley \& Duda, et al. [4-10], Flett [6] for example, found a positive correlation between flow and the performance of tennis players. In addition, researchers using music or hypnosis-based intervention strategies have shown a strong link between flow and the performance of golfers Pates, Oliver, \& Maynard, [9-11] basketball players Pates, Cummings, \& Maynard [12], badminton players Pates \& Palmi [13], footballers Pain, Harwood \&
Anderson [14], netball players Pates, Karageorghis, Fryer, \& Maynard [15] and cyclists Lindsay, Maynard, \& Thomas [16].

Recently the literature on Flow has been criticized for only partially explaining the peak performance experience (see Swann, Crust, Jackman, Vella, Allen, \& Keegan, 2017). Indeed, qualitative studies involving event focused interviews have suggested peak performances are also associated with a mental state called the 'Clutch' Swann et al. [1]. According to Swann et al. [1] . the Clutch state occurs during moments of extreme pressure when the athlete must 'make something happen'. This involves deliberate concentration, intense effort, and a heightened awareness. In contrast, Flow states occur spontaneously in the absence of effort when athletes 'let it happen'. Despite these differences research show that Clutch states and Flow states share similar characteristics, namely, confidence, absorption, perceptions of control, enhanced motivation, enjoyment, and altered sensory perceptions Swann et al. [1]. 
Athletes who have the ability to initiate Clutch states consistently deliver exceptional performances (clutch performances) in critical moments during important competitions see Hibbs [17]. According to Hibbs [17] this extraordinarily ability separates the winners from the losers and defines the great athletes we see in professional sports today. Without equivocation, interventions that train athletes to develop this ability would have a strong appeal to all practitioners in the applied sports psychology community. An aim of this study was to develop an intervention strategy that achieves this objective. The strong association between Clutch states and Flow states see Swann et al. [1] suggest interventions designed to enhance Flow may also be used to augment a Clutch state experience. Previous research suggests hypnosis-based interventions may be used for this purpose. The current study attempted to test this hypothesis by evaluating the effectiveness of a hypnosis-based intervention on Clutch states and golf performance. Golf was chosen as an ideal sport for this study because it involves producing a Clutch state and a Clutch type performance see Hibbs, [17] on every hole that is played. This is no more so apparent in the professional game where low scores on every hole are required to compete for prize money. Professional players were therefore chosen for this study.

To the authors knowledge, interventions that train athletes to control Clutch states do not exist. Using an intervention strategy partially based on the work of Pates [11] it was expected that during hypnosis a golfer's Clutch state experience could be conditioned to a trigger. It was then expected that after conditioning, golfers using the trigger would shoot lower golf scores.

An ideographic $\mathrm{AB}$ single-subject, multiple baseline across individual design was chosen to study the effects of the intervention on performance. This experimental design was deemed the most appropriate for this study because it facilitates the analysis of the effects of an intervention that could not be withdrawn from the participant due to the ethical reason of withholding a potentially positive intervention from an elite participant see Robson, [18]. In addition, to collecting performance data, Clutch states were analyzed using a procedure that monitored the internal experience of the player see Lerner, Ostrow, Yura, \& Etzel [19-22].

\section{Method}

\section{Participants}

The participants were three male professional golfers aged 27, 35 and 36, with 5 to 10 years of professional tour playing experience. All participants had a swing coach and over their playing careers had received only technical training. Although the golfers reported the swing training had been successful and it had helped them become professional athletes, they all felt during competitions when they had a chance to win, they struggled under pressure. It was therefore deemed appropriate to give these golfers an intervention that would improve their performance and play under pressure. The golfers in this study had no experience of hypnosis training administered by a qualified practitioner. All the golfers gave consent to take part in the study and received no other training during this experiment.

\section{Experimental Design}

An ideographic $A B$ single-subject, multiple-baselines, across subjects, design was implemented to examine the effects of a hypnosis-based intervention on golf performance in elite players. This type of design allows participants to serve as their own source of control for the experiment Barlow \& Herzen, [23, 24]. This format was also most appropriate because it facilitates the analysis of the effects of an intervention that could not be withdrawn from the participant due to the ethical reason of withholding a potentially positive intervention from an elite participant see Robson, [18].

The design required the observation of baseline performance and a treatment phase for each of the participants with the length of baseline increased for each succeeding player used in the analysis. The intervention was introduced when a stable baseline or a trend in the opposite direction of the change anticipated became apparent for each of the participants. A sequential application of the treatment (hypnosis intervention) was applied until all participants received the intervention. Based on the recommendations of Barlow and Hersen et al. [23, 25, 26] data were collected on 11 occasions over 16 weeks of tournament golf.

\section{Dependent Variables}

Performance analysis. Stroke average was selected as the performance indicator because it represents a global measure of the participant's overall performance. Stroke average is the average score taken from two or four rounds of stroke-play golf. A round of stroke-play golf consists of 18 holes wherein the participant records the number of strokes taken to complete each hole. At the end of the round, the scores from each hole are summed to give a total stroke-play score. The reliability of the stroke-play scores was assessed by comparing the judgments of the participant against an independent observer, who was the participant's playing partner. The reliability assessment took place after each round and resulted in a correlation of 1.00 for the scores of the participant and the independent observer. It is worth noting that a failure to score stroke-play correctly would result in a disqualification of the participant from the tournament. Scores were obtained from the official championship scorekeeper.

\section{Treatment: The Hypnosis-Based Intervention}

In this study the training of the participants took place immediately after the completion of the first baseline and was divided into four stages. In the first stage of the intervention, the researcher made sure the participants were familiar with the term 'Clutch states' by asking the participants to describe one of their experiences. When the researcher was satisfied with their descriptions, the training continued. Participants were encouraged to sit in a comfortable position and then was asked to focus on their breathing. Specifically, they were instructed to breathe deeply and 
to release air slowly while counting backwards from the Number 10. They were then given a 15-minute session involving progressive muscular relaxation (PMR). The technique, originally pioneered by Jacobson [27], involved the golfers tensing and relaxing parts of his body while deeply inhaling. Suggestions asking the participants to contrast the differences between the tense and the relaxed muscles were given along with instructions to direct their attention to images of situations that were associated with relaxation. For example, the external image of a warm comfortable beach or the internal sensation of floating in water.

In the second stage, an Erickson Ian hypnosis technique known as a staircase induction Hammond, [28] was applied. The staircase induction consisted of a journey, one step at a time, down a flight of 20 stairs. As the participants took the journey, they were told to see each stair in front of him and feel the stair under their feet. At the bottom of the stairs, they were told they would see a door and beyond the door they would see a room with a comfortable chair. The participants were then asked to sit down in the chair and to focus on a small cinema screen on which appeared a relaxing scene. Throughout this stage, suggestions were given to reinforce both the experience of the PMR, the deep breathing, and imagery techniques. In the third stage, suggestions were given to help the participants regress and remember a multisensory experience of a multisensory image of a clutch situation where they had to make a putt or shot to win an important event. The feelings and cognitions associated with a clutch performance was then conditioned to be released by a trigger. The trigger used was a verbal phrase "lets hole this shot". They were then asked to play a round of golf in their mind and include the multisensory image of holing all of their approach shots from the fairways, holing every chip shot from around the greens and holing all of their putts on the greens using their trigger words.

The participants were then told to see themselves rising from the chair and proceeding out the door and up the staircase. They were also told as they ascended the staircase that they would feel refreshed and alert. Once the participants reacclimatized to the environment, they were asked to access their clutch performance state by utilizing the trigger. This stage of the training was considered complete when the participants felt that feelings associated with the clutch state was under conscious control. In the final stage of the training, the participants were led to the golf course and encouraged to play 18 holes using a pre-shot routine that involved using the trigger before every approach shot, chip shot and putt in a pre-shot routine Training was considered complete when the participants felt the feelings and cognitions associated with the clutch state could be accessed under normal playing conditions. It should be noted these procedures were partially based on the intervention strategy developed by Pates [11].

\section{Intervention Procedures}

Ethical approval for the study was granted by the University ethics committee. All participants provided informed consent af- ter the researcher had explained the general purpose of the study. The hypnosis intervention was administered to the participants in a small, quiet, and comfortable room in the club house and lasted approximately 40 minutes. The training comprised three stages: Stage 1, hypnotic induction; Stage 2, hypnotic regression; and Stage 3, trigger control. After the hypnosis intervention the athletes played 18 holes of golf using the trigger in a pre-shot routine. This stage lasted approximately 4 hours. After completing the first training session, the participants were asked to commit themselves to 5 days of training where the procedures were repeated. In total, the player was given 5 live sessions and 5 rounds of golf before the intervention phase. The quality of the players experiences was assessed by examining their thoughts, feelings, and cognitions immediately after each session. Finally, it should be noted that during the intervention stage the players were not under hypnosis, instead they were merely using the trigger as part of their pre-shot routine.

\section{Practical Assessment Questionnaire}

During the 11 tournaments, the internal experience of the participants was monitored using an assessment questionnaire that included two open ended semi-structured interview questions:

1. Can you tell me what you experienced during the performance?

2. Can you describe what you were thinking and feeling during the performance?"

The interview questions were adapted from Kazdin et al. [9, $11,26,29]$. This information permitted ongoing assessment of the quality of the participant's feelings, thoughts, and cognitions across the baseline and treatment phases. The data were analyzed by comparing the comments obtained in the baseline sessions to the comments obtained during the intervention phase of the experiment.

\section{Social Validation Questionnaire}

Following the completion of the intervention phase, the participants were asked a series of questions to assess the social validity of the intervention. This method was used because it ties the intervention effects to the social context (competitive golf) and enables the researcher to demonstrate that changes in the dependent variable is the result of the intervention. It also provides an appropriate framework for examining client satisfaction see Kazdin, 1982; Milne et al. [30-33]. The questions in this study were designed to provide information on client satisfaction and the importance and effectiveness of the intervention. Based on the recommendations of Page and Thelwell, [32] and the work of Pates et al. [30] the participants were asked the following open ended semi-structured interview questions:

1. Can you tell me how satisfied you were with the intervention?

2. What are your thoughts regarding the importance and effectiveness of the intervention? 


\section{Data Analysis}

The performance scores and global (FSS-2) scores were plotted onto two graphs. Based on the guidelines put forward by Hrycaiko and Martin [24], an experimental effect was analyzed through a visual inspection of the plotted data. According to these researchers, the intervention had an effect when (a) baseline performance is stable or in a direction opposite to that predicted for the effects of treatment, (b) the greater the number of times that an effect is replicated within the subject's data (c) the fewer the number of overlapping data points between baseline and treatment phase, (d) the sooner the effect occurs following the introduction of treatment, and (e) the larger the size of the effect in comparison to baseline.

\section{Results}

\section{Performance Data}

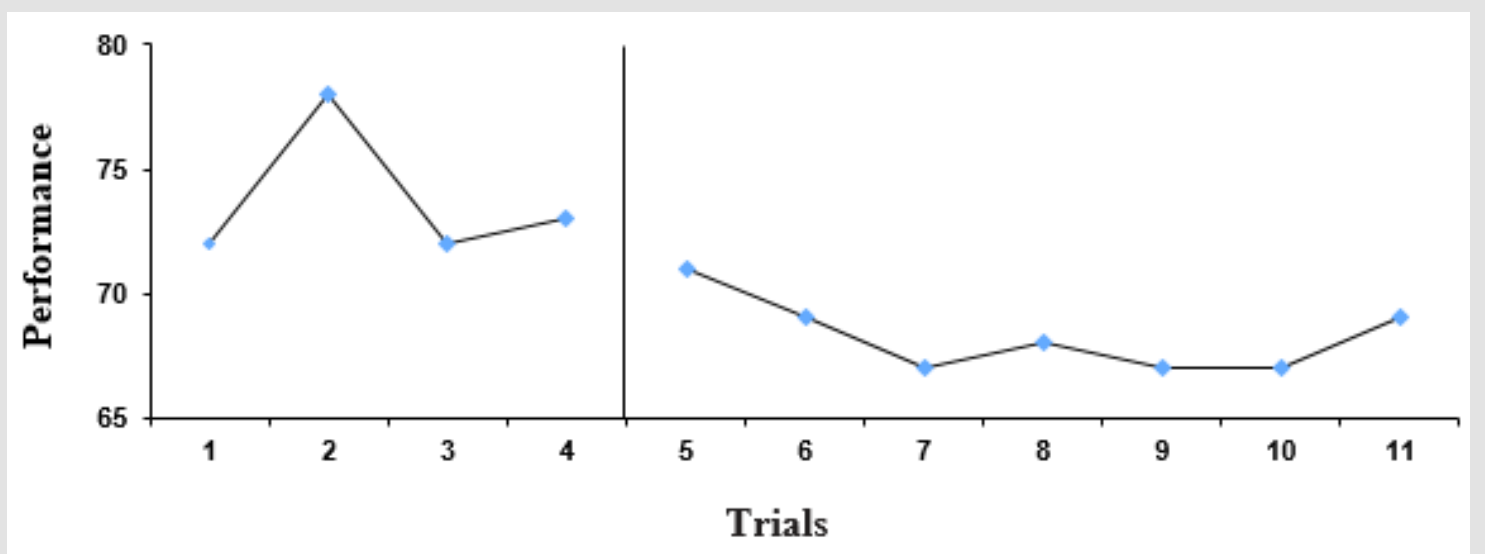

Figure 1: Stroke Average for Participant 1 for each trial.

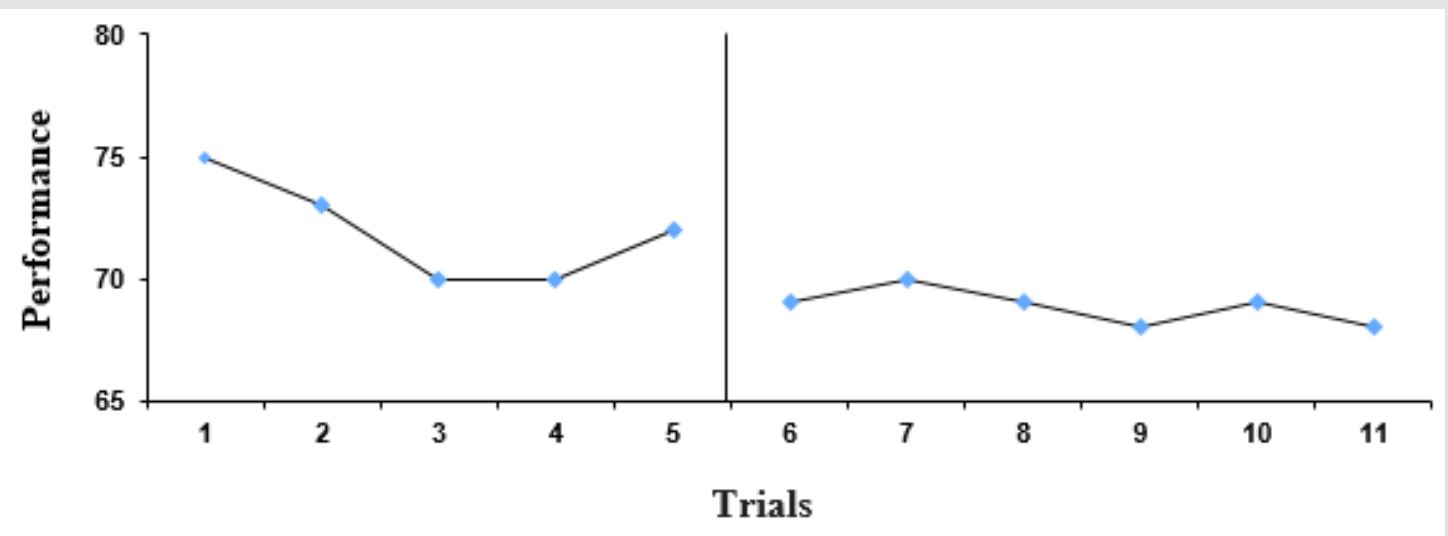

Figure 2: Stroke Average for Participant 2 for each trial.

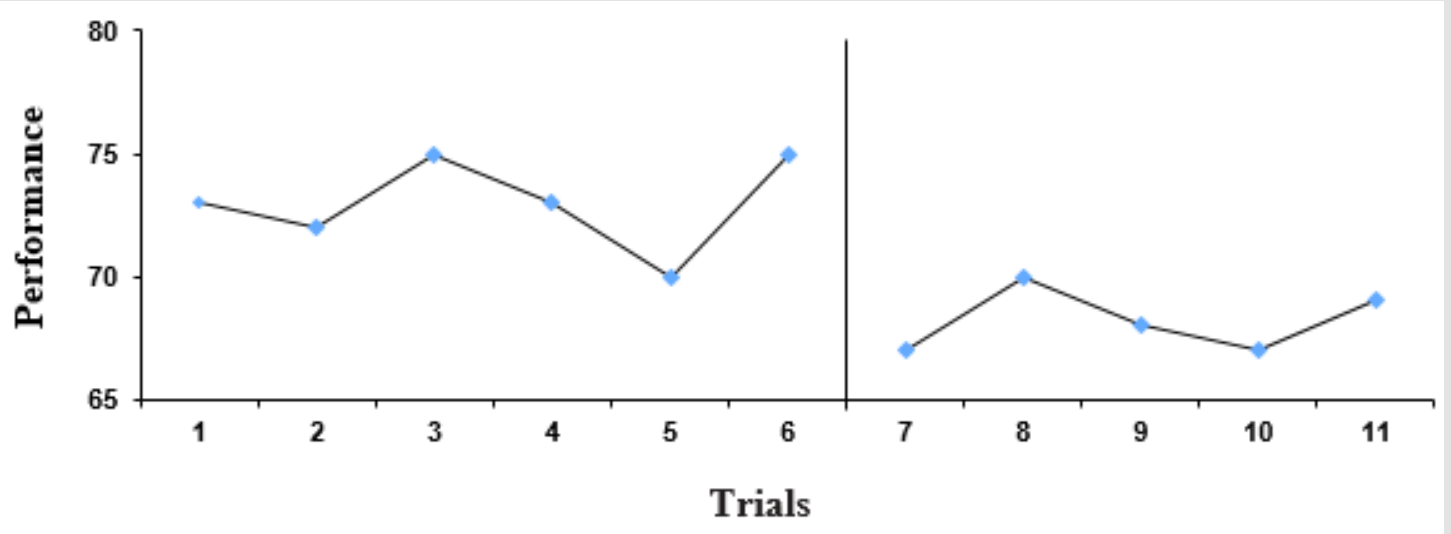

Figure 3: Stroke Average for Participant 3 on each trial. 
Upon receiving the intervention, the participants experienced an immediate performance effect with few overlapping data points between the baseline and the intervention phase. Specifically, participant 1 improved his performance from a mean of 73.7 during the baseline to a mean of 68.2 during the intervention phase, there were no overlapping data points in his performance data (Figure 1). Participant 2 improved his performance from a mean of 72.0 during the baseline to a mean of 68.8 during the intervention phase, there was 1 overlapping data point in his performance data (Figure 2). Participant 3 improved his performance from a mean of 73.0 during the baseline to a mean of 68.2 during the intervention phase, there was 1 overlapping data point in his performance data (Figure 3). Taken together the results suggest that the Hypnosis intervention consistently improved the performance of professional golfers playing in real European tour events.

\section{Practical Assessment Data}

After finishing each tournament, the participants responded to the practical assessment questionnaire. This helped the researcher examine the player's internal experience during tournament golf All three participants indicated that during the tournaments (the intervention phase) they felt "more focused on the task," experienced "improved concentration," "intensity", "effort" and "commitment" to their shots". They also reported several emotions that included excitement, confidence and fun. Pressure and mental fatigue were also reported as undesirable outcomes. Participant 2 reported "the idea of holing everything was exciting". "It made me feel the way I did when I first started playing golf". "I felt I was completely focused on what I had to do". "I could not wait to find out if I could make the next shot the way my mind was telling me". "The routine also improved my commitment to shots which is really important for me". "It stopped me just going through motions". Participant 1 reported "I played great golf, but I was exhausted after my game"

Another important finding was participant's 1 report about his confidence and perceptions. "I got the feeling I could hole everything, and I felt I can make the impossible happen. It was like playing my dream round of golf where I could just will the ball into the hole". In addition, participant 2 reported some strange perceptions that can only be described as intuitive thoughts. "I chipped in a few a few times, more often than I usually do, the weird thing was I knew those shots were going in before I hit them". "It was a strange feeling".

\section{Social Validation Data}

Finally, it should be noted that the social validation questionnaire revealed that all three participants were extremely satisfied with the results of the intervention and recognized that the intervention had improved their performances and prize money. Participant 1 reported "the training had helped me keep my tour card'. Participant 2 reported "I have won more prize money in the last few weeks than the whole year". Participant 3 reported "I've had more top ten finishes since I started the training and I almost won the Portuguese open".

\section{Discussion}

The present study demonstrated that a hypnosis-based intervention strategy may have a positive effect on the performance of elite golfers. Clutch State experiences also appeared to be enhanced by the intervention. The results are consistent with previous research by Pates [11] who showed that improved performances can be achieved with techniques designed to activate mental states that are associated with peak performances. The practical assessment data revealed some interesting findings. First, the data show that the intervention appears to enhance a number of variables associated with previous reports on Clutch states, namely, pressure, concentration, intensity and effort (see Swann et al. [1]). Second, the intervention appeared to augment positive emotions such as excitement, confidence and fun, and third, the technique seemed to alter the golfer's perceptions making them believe they can produce an exceptional performance outcome such as holding improbable shots.

The finding that this hypnosis-based intervention enhanced self-confidence making the participants believe they can produce exceptional performances is worth highlighting because there is a wealth of evidence that suggest self-confidence is one of the most important psychological variables associated with optimal performance in sport (see Feltz, Short, \& Sullivan, [34]). This essential finding supports the work of Barker and Jones [35-36] who found a hypnosis intervention enhanced the confidence and performance of Footballers, Judo athletes and Cricketers. It also offers further support for utilizing Hypnosis intervention strategies when working in elite sport. In addition, to the practical assessment data the social validation data provided further evidence for the positive effect of hypnosis on performance. Indeed, all of the participants reported the intervention had improved their scores and increased their prize money. In addition, all three participants reported they were satisfied with the results. The implications of these findings are far reaching for sport psychologists, because they suggest elite golfers should use hypnosis-based interventions to prepare for major competitions.

A clear strength of this study is its ecological validity; rarely have elite golfers using a Hypnosis-based intervention been studied during professional golf tournaments. Another important aspect of the present study was that the $\mathrm{AB}$ single-subject, multiple baseline, across individuals design enabled the experimenter to be more confident that the change in performance scores were produced by the intervention and not some other uncontrollable variable. Indeed, the demonstration of a performance effect when the intervention was introduced gave a very clear demonstration that the intervention had some degree of external validity (Kazdin, [26]). The possibility remains, of course, that the positive results are an artifact of both participant and experimenter bias. Indeed, neither were blind to the outcome and so experimenter expectations or the demand characteristics of the experiment may have influenced the results (Kazdin, [26]). There may also have been either a Hawthorne 
or Rosenthal effect (Rosenthal \& Rosnow, [37]). Scrutiny of a performer in a single-subject experimental design might heighten these effects. However, as Drew [38] observed, these effects tend to decline as the participants become acclimatized to being studied, so the extended length of the single-subject study could aid in controlling for this effect.

In conclusion, the results of the study suggest hypnosisbased interventions are an effective way of preparing elite golfers for significant competitions. This discovery supports the work of Unestahl [10,39] who explicitly indicated that elite athletic populations should be trained using hypnosis-based techniques. However, in order to improve the external validity of these results, this experiment needs to be replicated using quantitative measures of clutch states and different athletic populations. Large scale controlled randomized designs are also needed to support the study's findings [40-45]. Based on the positive results of this study the researcher has a number of suggestions for the sport psychology community. First, attitudes and opinions regarding how to train elite athletic populations need to be changed within the applied sports psychology community. Second, sports psychologists need to be familiarized and skilled in using hypnosis techniques. Third, scientific and professional societies in sport should consider training for individuals in the use of hypnosis intervention strategies [46-53].

\section{References}

1. Swann C, Crust L, Jackman P, Vella S, Allen M S, et al. (2017) Psychological States Underlying Excellent Performance in Sport: Toward an Integrated Model of Flow and Clutch states. Journal of Applied Sport Psychology 29(4) 375-401.

2. Wollman N (1986) Research on imagery and motor performance: Three methodological suggestions. Journal of Sport Psychology 8(2): 135-138.

3. Privette G (1983) Peak experience peak performance and flow: A comparative analysis of positive human experiences. Journal of Personality and social Psychology 6: 1361-1368.

4. Catley D, Duda J (1997) Psychological antecedents of the frequency and intensity of flow in golfers. International Journal of Sport Psychology 28 309-322.

5. Cohn P (1991) An exploratory study of peak performance in golf. The Sport Psychologist 5(0): 1-14.

6. Flett MR (2015) Is Flow Related to Positive Feelings or Optimal Performance? Path Analysis of Challenge-Skill Balance and Feelings. Sport Science Review 24: 5-26.

7. Jackson SA, Roberts GC (1992) Positive performance states of athletes: Toward a conceptual understanding of peak performance. The Sport Psychologist 6(2): 156-171.

8. Nakamura J, Csikszentmihalyi M (2014) The concept of flow. In M Csikszentmihalyi (Ed) Flow and the foundations of positive psychology 239-263.

9. Pates J K, Oliver R, Maynard I (2001) The effects of hypnosis on Flow states and golf putting performance. Journal of Applied Sport Psychology 13(1): 341-354.

10. Unestahl LE (1983) Inner mental training. Veje Publications Orebro Sweden.

11. Pates J K (2013) The effects of hypnosis on an elite senior European tour golfer: a single subject design. Intl. Journal of Clinical and Experimental Hypnosis 61(2): 193-204.
12. Pates J K, Cummings A, Maynard I (2002) The effects of hypnosis on Flow states and three-point shooting performance in basketball players. The Sport Psychologist 16(1): 34-47.

13. Pates J K, Palmi J (2002) The effect of hypnosis upon Flow states and short serve badminton performance. Journal of Excellence 6: 48-62.

14. Pain MA, Harwood C, Anderson R (2011) Pre-competition imagery and music: The impact on flow and performance in competitive soccer. The Sport Psychologist 25(2): 212-232.

15. Pates J, Karageorghis C I, Fryer R, Maynard I (2003) Effects of asynchronous music on Flow states and shooting performance among netball players. Psychology of Sport and Exercise 4(4): 415-427.

16. Lindsay P, Maynard I W, Thomas O (2005) Effects of hypnosis on Flow states and cycling performance. The Sport Psychologist 19(2): 164-178.

17. Hibbs D (2010) A conceptual analysis of clutch performances in competitive sports. Journal of the Philosophy of Sport 37(1): 47-59.

18. Robson C (1994) Real world research: A resource for social scientists and practitioner- researchers. Oxford United Kingdom: Blackwell.

19. Lerner BS, Ostrow AC, Yura MT, Etzel EF (1996) The effects of goal setting and imagery training programs on the free-throw performance of female collegiate basketball players. The Sport Psychologist 10(4): 382-397.

20. Smith RE (1988) The logic and design of case study research. The Sport Psychologist 2(1): 1-12.

21. Swain ABJ, Jones G (1995) Goal attainment scaling: Effects of goal setting inter- on selected sub-components of basketball performance. Research Quarterly for Exercise and Sport 66: 51-63.

22. Wollman N (1986) Research on imagery and motor performance: Three methodological suggestions. Journal of Sport Psychology 8(2): 135-138.

23. Barlow DH, Hersen M (1984) Single case experimental designs: Strategies for studying behavior change $\left(2^{\text {nd }} E d n\right.$.), New York NY: Pergamon.

24. Hrycaiko DW , Martin GL (1996) Applied research studies with single subject designs: Why so few? Journal of Applied Sport Psychology 8 (2): 183-199.

25. Barlow DH, Hersen M (1973) Single case experimental designs: Uses in applied clinical research. Archives of General Psychiatry 29(3): 319-325.

26. Kazdin AE (1992) Research design in clinical psychology. New York NY: Macmillan. Kendall G.

27. Jacobson E (1938) Progressive relaxation (2 ${ }^{\text {nd }}$ Edn.), Chicago IL: University of Chicago Press.

28. Hammond D C (1990) Handbook of hypnotic suggestions and metaphors. New York NY: Norton.

29. Kendall G, Hrycaiko D Martin G L, Kendall T (1990) The effects of an imagery rehearsal relaxation and self-talk package on basketball game performance. Journal of Sport \& Exercise Psychology 12: 157-166.

30. Pates J K, Maynard I, Westbury A (2001) The effects of hypnosis on basketball performance. Journal of Applied Sport Psychology 13: 84102.

31. Milne D (Ed) (1987) Evaluating mental health practice. Worcester UK: Billin \& Sons

32. Page J, Thelwell R (2013) The Value of Social Validation in Single-Case Methods in Sport and Exercise Psychology. Journal of Applied Sport Psychology 25(1): 61-71.

33. Storey K, Horner RH (1991) An evaluative review of social validation research involving persons with handicaps. Journal of Special Education 25(3): 352-401.

34. Feltz DL, Short SE, Sullivan PJ (2008) Self efficacy in sport. Champaign IL: Human Kinetics.

35. Barker JB, Jones MV (2005) Using hypnosis to increase self-efficacy: A case study in elite judo. Sport and Exercise Psychology Review 1: 36-42. 
36. Barker J B Jones M V (2008) The effects of hypnosis on self-efficacy affect and sport performance: A case study from professional English soccer. Journal of Clinical Sport Psychology 2: 127-147.

37. Rosenthal R, Rosnow RL (2008) Essentials of behavioral research: Methods and data analysis ( $3^{\text {rd }}$ Edn.), New York NY: McGraw Hill.

38. Drew CJ (1976) Introduction to designing and conducting research. St Louis MO: C V Mosby.

39. Unestahl LE (1986) Self-Hypnosis. In J Williams Applied Sport Psychology: Personal growth to peak performance. Mayfield.

40. Barker JB, Jones MV (2006) Using hypnosis technique refinement and self- modeling to enhance self-efficacy: A case study in cricket. The Sport Psychologist 20: 94-110.

41. Crawford HJ, Clarke SW, Kitner-Triolo M (1996) Self-generated happy and sad emotions in low and highly hypnotizable persons during waking and hypnosis: Laterality and regional EEG activity differences. International Journal of Psychophysiology 24(3): 239-266.

42. Csikszentmihalyi M (1990) Flow: The psychology of optimal experience. New York NY: Harper \& Row.

43. Damaser EC, Shor RE, Orne MT (1963) Physiological effects during hypnotically requested emotions. Psychosomatic Medicine 25: 334-343.

44. Jackson SA (1999) Joy fun and flow state in sport In Y Hanin (Ed) Emotions in sport 135-155.

45. Jackson SA, Csikszentmihalyi M (1999) Flow in sports: The keys to optimal experiences and performances. Champaign IL US: Human Kinetics Books.

\section{ISSN: 2574-1241}

DOI: $10.26717 /$ BJSTR.2019.23.003863

John Pates. Biomed J Sci \& Tech Res

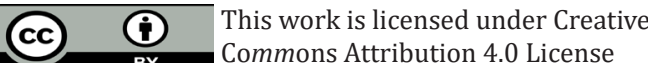

Submission Link: https://biomedres.us/submit-manuscript.php
46. Jackson SA, Eklund RC (2002) Assessing flow in physical activity: The Flow State Scale-2 and the Dispositional Flow Scale-2. Journal of Sport \& Exercise Psychology 24(2): 133-150.

47. Hrycaiko D, Martin GL, Kendall T (1990) The effects of an imagery rehearsal relaxation and self-talk package on basketball game performance. Journal of Sport \& Exercise Psychology 12(2): 157-166.

48. Kirsch I (1994) Defining hypnosis for the public. Contemporary Hypnosis 11 142-143.

49. Koehn S, Morris T, Watt AP (2014) Imagery Intervention to Increase Flow State and Performance in Competition. Sport Psychologist 28(1): 48-59.

50. Nicholls AR, Polman RC, Holt NL (2005) The effects of an individualized imagery interventions on Flow states and golf performance. Athletic Insight 7(1): 43-66.

51. Pates JK, Maynard I, (2000) Effects of hypnosis on Flow states and golf performance. Perceptual and Motor Skills 91(3): 1057-1075.

52. Privette G (1983) Peak experience peak performance and flow: A comparative analysis of positive human experiences. Journal of Personality and social Psychology 6: 1361- 1368.

53. Wadden T A, Anderton C H (1982) The clinical use of hypnosis Psychological Bulletin 91: 215-243.

$\begin{array}{ll}\text { BIOMEDICAL } & \text { Assets of Publishing with us } \\ \text { RESEARCHES } & \text { - Global archiving of articles } \\ \text { - Immediate, unrestricted online access } & \text { - Rigorous Peer Review Process } \\ & \text { - Authors Retain Copyrights } \\ \end{array}$

